\title{
A nation-wide retrospective epidemiological study of gastroenteropancreatic neuroendocrine neoplasms in china
}

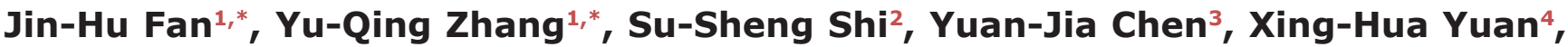 \\ Li-Ming Jiang ${ }^{5}$, Shao-Ming Wang ${ }^{1}$, Li $\mathrm{Ma}^{6}$, Yu-Tong $\mathrm{He}^{7}$, Chang-Yan Feng ${ }^{8}$, Xi-Bin \\ Sun ${ }^{9}$, Qing Liu ${ }^{10}$, Katrina Deloso ${ }^{11}$, Yihebali Chi ${ }^{12}$ and You-Lin Qiao ${ }^{1}$ \\ ${ }^{1}$ Department of Cancer Epidemiology, Cancer Hospital, Chinese Academy of Medical Sciences \& Peking Union Medical \\ College \\ ${ }^{2}$ Department of Pathology, Cancer Hospital, Chinese Academy of Medical Sciences \& Peking Union Medical College \\ ${ }^{3}$ Department of Gastroenterology, Peking Union Medical College Hospital, Peking Union Medical College, Chinese Academy \\ of Medical Sciences \\ ${ }^{4}$ Department of Abdominal Surgery, Cancer Hospital, Chinese Academy of Medical Sciences \& Peking Union Medical College \\ ${ }^{5}$ Department of Radiology, Cancer Hospital, Chinese Academy of Medical Sciences \& Peking Union Medical College \\ ${ }^{6}$ Department of Epidemiology, Dalian Medical University \\ ${ }^{7}$ Hebei Cancer Registry, the Fourth hospital of Hebei medical university \\ ${ }^{8}$ Department of Nutrition, Chongqing Cancer Hospital \& Institute \& Cancer Center \\ ${ }^{9}$ Department of Cancer Epidemiology, Henan Cancer Hospital/Institute \\ ${ }^{10}$ Department of Cancer Prevention, Sun Yat-sen University Cancer Center \\ ${ }^{11}$ Division of Biological Sciences, the University of Chicago \\ ${ }^{12}$ Department of Medical Oncology, Cancer Hospital, Chinese Academy of Medical Sciences \& Peking Union Medical College \\ "These authors have contributed equally to this work \\ Correspondence to: You-Lin Qiao, email: Qiaoy@cicams.ac.cn \\ Yihebali Chi, email: yihebalichi@hotmail.com
}

Keywords: neuroendocrine tumors, digestive system, epidemiology, retrospective study multicenter study

Received: October 20, $2016 \quad$ Accepted: April 11, $2017 \quad$ Published: May 03, 2017

Copyright: Fan et al. This is an open-access article distributed under the terms of the Creative Commons Attribution License 3.0 (CC BY 3.0), which permits unrestricted use, distribution, and reproduction in any medium, provided the original author and source are credited.

\section{ABSTRACT}

Background: Representative data on the gastroenteropancreatic neuroendocrine neoplasms (GEP-NENs) in Asian patients is rare, especially in China. This study aims to create a GEP-NENs profile of Chinese patients.

Methods: This was a hospital-based, nation-wide, and multi-center 10-year (2001-2010) retrospective study which collected GEP-NEN patients' information in tertiary referral hospitals. All 2010 inpatient GEP-NEN cases with confirmed pathology in the selected hospitals were included. The primary GEP-NEN sites were measured and the epidemiological and clinical information of each tumor site were compared.

Results: The most common primary sites for GEP-NEN were the pancreas $(31.5 \%)$ and rectum $(29.6 \%)$, followed by the cardia (11.6\%) and body $(15.4 \%)$ of stomach. Small intestinal and colonic NENs took up a relatively small proportion of all patients. Pancreatic and rectal NENs, rather than cardiac and gastric body NENs, tended to be found in younger $(P<0.001)$, female $(P<0.001)$, urban $(P<0.001)$ residents with a higher education level $(P=0.032)$ and were also diagnosed at earlier stage $(P<0.001)$ and lower grade $(P<0.001)$. Surgery remained the primary treatment method in all groups.

Conclusions:More studies on the commonality and heterogeneity of GEP-NENs are warranted to improve diagnosis efficiencies and treatment outcomes. 


\section{INTRODUCTION}

Neuroendocrine neoplasms (NENs) arise from cells throughout the diffuse endocrine system and are characterized by their ability to produce peptides that cause distinctive hormonal syndromes. NENs in the tubular digestive tract (including the pancreas) are known as gastroenteropancreatic neuroendocrine neoplasms (GEP-NENs).

Since the 1900's, when Oberndorfer coined the name 'karzinoide' to describe submucosal neoplasms in small intestines [1], many nomenclatures systems have emerged. William and Sandler [2] classified all neuroendocrine neoplasms as foregut, midgut, or hindgut neoplasms according to their embryological origins, which covered the diverse features. The World Health Organization (WHO) provided a classification system in 2000 [3] based on a combination of pathological and clinical parameters, subsequently, the European Neuroendocrine Tumor Society (ENETS) $[4,5]$ and the American Joint International Cancer/ Union of International Cancer (AJCC/UICC) [6] proposed classification systems including TNM stage (the inherent biologic aggressiveness of the tumor), and grade (which refers to similarities between neoplastic cells and their non-neoplastic counterparts). Later classification systems, including WHO 2010, included both stage and grade systems. This lack of consensus on classification resulted in difficulty in investigating the epidemiology of GEP-NENs [7].

Several studies have revealed that the incidence of malignant neuroendocrine neoplasms (NENs) has been steadily increasing. The Surveillance, Epidemiology, and End Results (SEER) program [8] showed an increase from 1.09 new cases per 100,000 in 1973 to 5.25 per 100,000 in 2004, with 2.65 times as many GEP-NEN incidences in 2007 as there were in 1973 [9]. In the UK, gastrointestinal NEN (excluding pancreatic NENs) incidence increased by 4.8 and 3.8 times in males and females, respectively, from the 1970s to the years between 2000 and 2006 [10]. Furthermore, in the US, GEP-NEN incidence and predilection site differed between Caucasians, African Americans, and Asian/Pacific Islanders, suggesting a racial disparity in NENs [8]. Studies from Asian countries on this rare cancer have emerged recently and all revealed epidemiological inequalities with American and European countries [11-13]. Large-scale surveys are needed in mainland China to gather sufficient data on the features of this tumor. In this paper, we retrospectively collected epidemiological information and studied the current diagnosis and treatment of pathology-confirmed GEPNEN cases in the past decade on a national scale.

\section{RESULTS}

A total of 2,049 clinical records were retrieved from 23 hospitals. Eight cases were excluded because they involved tumors that had initially formed in the gallbladder and liver, and an additional 31 cases were excluded because the patients suffered from more than one type of cancer and the specimens in hospital were adenocarcinoma or squamous carcinoma. As a result, a final total of 2,010 patients were included, and of which 871 from specialized cancer hospitals and 1,139 came from general hospitals.

\section{Patients' characteristics}

Age range of the GEP-NEN patients was 8-89 years. Distribution of age did not comply with normal distribution $(\mathrm{P}=0.002)$, and the median age was 53.0 years (inter-quartile range: 20.0 years). The peak age group at diagnosis was 50-60 years. The sex ratio (men/women) was 1.4/1 (1169/841); $178(35.4 \%)$ of 503 cases lacked a middle school education; $93.9 \%$ (1877 in 1999) of patients were married; and 1300 (68.1\%) of 1909 cases with household registration information were urban residents (the remaining 609 were rural residents).

Of the 2,010 GEP-NEN cases, pancreatic NENs took up the majority, at $31.5 \%$ (633 cases), followed by rectal NENs at $29.6 \%$ (595 cases), gastric body NENs at $15.4 \%$ (309 cases) and cardiac NENs at 11.6\% (234 cases). NENs originating at other sites, including the small intestine, colon, appendix, as well as multiple endocrine neoplasms, accounted for a relatively small proportion (Figure 1). Figure 2 shows the changes in GEP-NEN case number in each group over 10 years. Patient numbers in all sites increased consistently, with the highest increase in rectal and pancreatic NENs. Further analysis shows that the case number increased more significantly in urban than in rural residents, especially after the year 2006. We also compare the trend of case increase with Chinese cancer incidence in 2001-2010 [14, 15] (Supplementary Figure 1), and they showed similar changes during 2001-2009 (the different reference group result in the significant high cancer incidence in 2010). Considering the limited number of cases, we put NENs from the small intestine, colon, appendix, multiple and unknown sites in a single group. Table 1 shows the distribution of demographic characteristics and possible risk factors in patients of each primary site. Pancreatic and rectal NEN patients were diagnosed at a younger age. Male patients comprised of a larger proportion of all cardiac, gastric body and rectal NEN patients, at $84.2 \%, 74.1 \%$ and $57.3 \%$, respectively, but female patients comprised of a larger proportion (58.8\%) of pancreatic NENs. In rectal and pancreatic NEN patients, urban residents contributed over twice as many cases as rural residents. This situation was reversed in cardiac NENs, while gastric body NENs showed a more even distribution. A higher education level was more commonly seen in rectal and pancreatic NEN patients than in cardiac and gastric body NEN patients. Family history of tumors seemed to increase risk more for cardiac and gastric body NEN patients than for rectal and pancreatic NEN patients. The distribution of smoking and alcohol use significantly differed between the five groups $(P<0.001)$. 


\section{Neoplasm stage and histological grade}

We received classification information for 1,903 cases, and $4.1 \%$ (81 cases) cases could not be classified due to insufficient information. Grading based on mitosis rate or the Ki-67 labeling index was explicit in 1,456 $(73.4 \%)$ cases. The stage and grade distribution in each site group were shown in Figure 3. Tumor stage $(P<0.001)$ and grade $(P<0.001)$ varied greatly based on primary tumor site: $77.4 \%$ of rectal and $72.4 \%$ of pancreatic NENs were diagnosed at the localized stage and at grades G1/ G2 (87.6\% and 90.2\%), while more cardiac and gastric body NENs (73.4\% and 67.7\%) displayed local invasion or distant metastasis at diagnosis. Among the 1,414 cases where both stage and grade information were available, we found that histological grade was strongly associated with disease stage $(P<0.001): 8.7 \%$ (of 732$)$ of G1 and $16.9 \%$ (of 219) of G2 NEN patients exhibited synchronous distant metastasis at diagnosis, whereas $17.7 \%$ (of 463) of G3 NEN patients had metastasis at diagnosis.

\section{Treatment methods}

Overall, 1,820 (90.5\%) of the GEP-NEN patients underwent surgery, of which more than $90 \%$ were curative and the rest were palliative. Palliative surgery was performed most frequently $(9.8 \%$ of all surgeries) in rectal NEN patients. Over $90 \%$ of the surgeries were performed as open surgeries for cardiac, gastric body and pancreatic NEN patients, and surgeries under endoscopy were performed most frequently on rectal NENs (28.4\%). A total of $393(20.0 \%)$ of 1,967 patients have underwent chemotherapy, separately or before surgery, with higher rates among cardiac and gastric body NEN patients. Biotherapy was given to 171 (27.5\%) of 621 pancreatic NEN patients but was uncommon for patients with other primary NEN sites. Other therapies, such as targeted therapy and radiotherapy were rarely used (Table 2).

\section{Clinical and pathologic characteristics}

Dyspepsia was the most common presenting symptom for patients with gastrointestinal neoplasms, and was seen in $12.4 \%$ of 1336 patients with valid data. Among patients with pancreatic NENs, $47.5 \%$ presented with Whipple triad symptoms, which were the most common hormone-related symptoms overall. Diarrhea was recorded in 139 cases. Most of them were in rectal NENs (75 cases), which comprised $12.6 \%$ of all rectum NEN patients. Flush and Zollinger-Ellison syndromes were respectively shown in 15 and 20 GEP-NEN cases. Verner-Morrison syndrome and glucagonoma syndrome was presented in 5 and 12 Pan-NEN patients, respectively. As shown in Table 3, rates of vascular space involvement, perineural invasion,

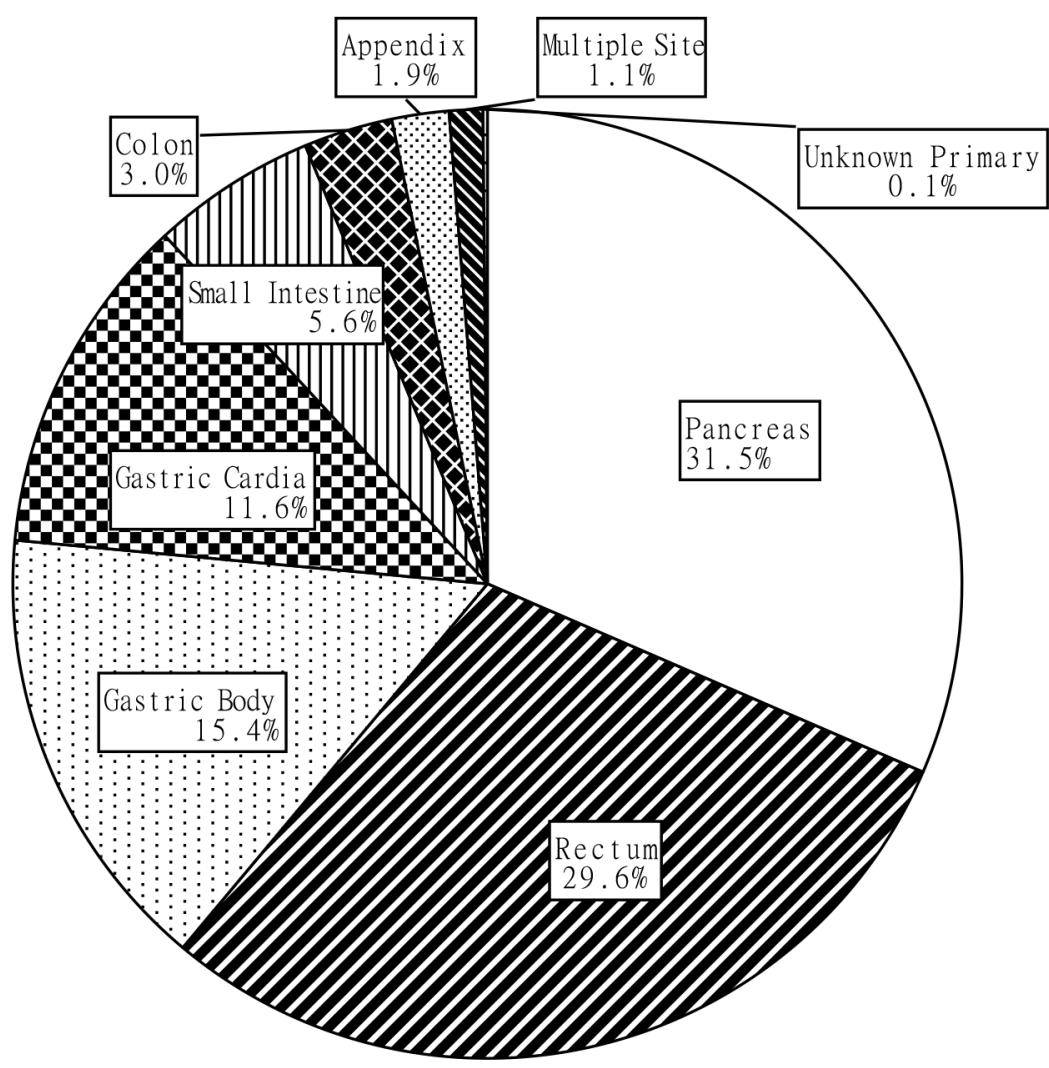

\section{Primary Site}

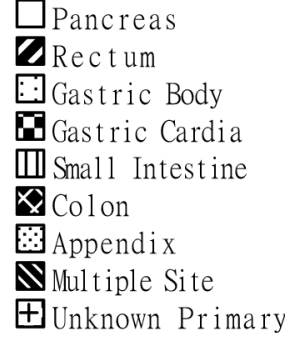

Figure 1: The proportion of primary tumor site in all cases. 
and necrosis were higher in cardiac, gastric body and pancreatic NENs, while cystic degeneration was more likely found in pancreatic NENs; rates of all of these differed according to the NEN sites $(\mathrm{P}<0.001)$. Among patients with biomarker test information, about $90 \%$ patients were positive for synaptophysin positive, a much higher rate than choromogranin A, CD56, neuron-specific enolase, S-100 protein, or CK (AE1/AE3).

\section{DISCUSSION}

Previous studies in China have revealed the clinical features of NENs in single center $[16,17]$, but this was the first geographically representative epidemiologic study for GEP-NEN. In this study, we reviewed information from 2,010 patients and assessed the general epidemiological characteristics, clinical symptoms and treatment information of GEP-NENs.

The most common GEP-NENs began in the pancreas, rectum and the stomach, each comprising almost $30 \%$ of all NENs, if we put the gastric cardiac and gastric body together. Small intestinal, colonic, and appendicular NENs were relatively rarely seen. Our findings significantly differed from SEER [9]. According to SEER 17 (2000-2007), the rectum and small intestine were the most common sites for NENs (29.2\% and 28.4\% of all GEP-NENs); followed by those in the pancreas and colon (11.5\% each), and finally those in the stomach and appendix were the least common (9.9\% and 5.1\%). Studies based on databases from Norway [18] and Switzerland [19] also revealed a high incidence of small intestinal and colorectal NENs, while the incidence of appendix NENs surpassed that of small intestinal and colorectal NENs in the UK [10]. These inconsistencies were due in part to racial disparities; Yao [8] reported that among Asians/Pacific Islanders in American, the incidence of rectal NENs patients was about 5 times that of small intestinal, pancreatic and gastric NENs, but these rates were not observed in Caucasians or African Americans. Studies in Korea [11] and Taiwan [13] found similar results to those of Asians/Pacific Islanders in America, reporting that incidence of rectal NENs was almost 3-4 times that of gastric, pancreatic, colon and small intestinal. Results from a Japanese study also found that midgut NENs accounted for only a small percentage of all NENs [12]. In addition, as the small intestinal NENs are always asymptomatic, and only by metastasis to the liver, watery diarrhea and flushing would be shown. Also, Small intestine is an organ which is hard to be accessed, and the tumor diagnose rate is more dependent to endoscopic procedures comparing to tumors of other sites. The low detection rate of small intestinal NEN in our study was

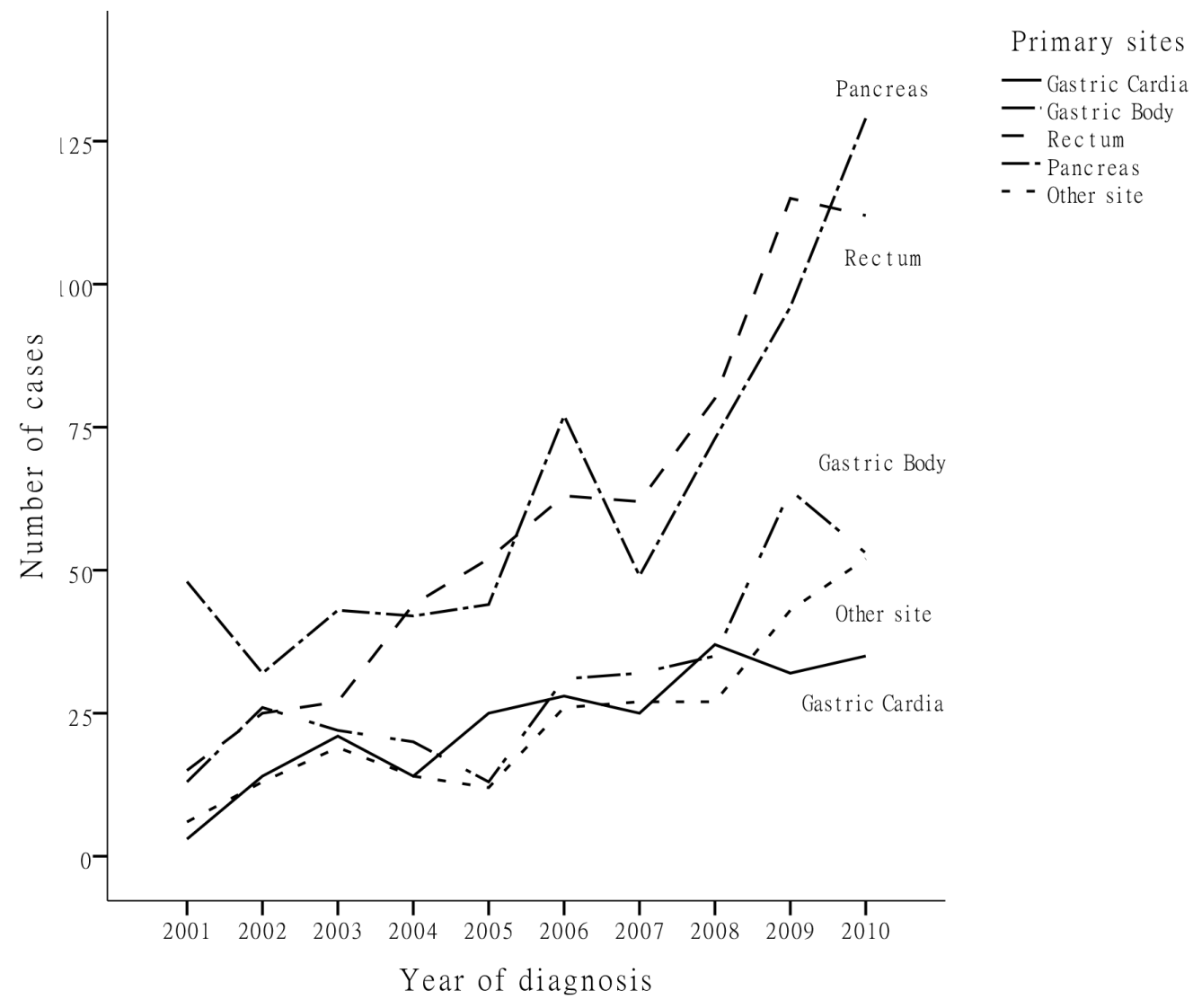

Figure 2: Number of patients diagnosed in each year. 
Table 1: Basic characteristics and potential risk factors of GEP-NENs patients

\begin{tabular}{|c|c|c|c|c|c|c|c|}
\hline Variables & $\begin{array}{c}\text { Total } \\
\text { distribution } \\
(\mathrm{N}=\mathbf{2 0 1 0})\end{array}$ & $\begin{array}{c}\text { Gastric } \\
\text { cardiac } \\
\text { NENs } \\
(\mathrm{N}=234)\end{array}$ & $\begin{array}{c}\text { Gastric } \\
\text { body NENs } \\
(\mathbf{N}=\mathbf{3 0 9})\end{array}$ & $\begin{array}{c}\text { Rectal } \\
\text { NENs } \\
(\mathbf{N}=595)\end{array}$ & $\begin{array}{c}\text { Pancreatic } \\
\text { NENs } \\
(\mathrm{N}=633)\end{array}$ & $\begin{array}{l}\text { Other NENs } \\
\qquad(\mathrm{N}=\mathbf{2 3 9})\end{array}$ & $P$ value \\
\hline & n (\%) & n (\%) & n (\%) & n (\%) & n (\%) & n (\%) & \\
\hline $\begin{array}{l}\text { Age at Diagnosis } \\
(\mathrm{M}, \mathrm{QR})\end{array}$ & $53.0,20.0$ & $61.0,12.3$ & $58.0,17.5$ & $51.0,18.0$ & $46.0,20.0$ & $53.0,22.0$ & $0.000 *$ \\
\hline Sex & $2010(100.0)$ & $234(100.0)$ & 309 (100.0) & $595(100.0)$ & $633(100.0)$ & 239 (100.0) & \\
\hline Male & $1169(58.2)$ & 197 (84.2) & $229(74.1)$ & $341(57.3)$ & $261(41.2)$ & $141(59.0)$ & $0.000 *$ \\
\hline Female & $841(41.8)$ & $37(15.8)$ & $80(25.9)$ & $254(42.7)$ & $372(58.8)$ & $98(41.0)$ & \\
\hline Region & $1909(100.0)$ & $227(100.0)$ & $291(100.0)$ & $566(100.0)$ & $596(100.0)$ & $229(100.0)$ & \\
\hline Rural & 609 (31.9) & 145 (63.9) & $125(43.0)$ & 103 (18.2) & $179(30.0)$ & $57(24.9)$ & $0.000 *$ \\
\hline Urban & $1300(68.1)$ & $82(36.1)$ & $166(57.0)$ & $463(81.8)$ & $417(70.0)$ & $172(75.1)$ & \\
\hline Education level & $503(100.0)$ & $31(100.0)$ & $64(100.0)$ & $202(100.0)$ & $122(100.0)$ & $84(100.0)$ & \\
\hline $\begin{array}{l}\text { Below middle } \\
\text { school }\end{array}$ & $178(35.4)$ & $15(48.4)$ & $30(46.9)$ & $70(34.7)$ & $32(26.2)$ & $31(36.9)$ & $0.032 *$ \\
\hline $\begin{array}{l}\text { Middle school or } \\
\text { above }\end{array}$ & $325(64.6)$ & $16(51.6)$ & $34(53.1)$ & $132(65.3)$ & $90(73.8)$ & $53(63.1)$ & \\
\hline Body Mass Index & $1132(100.0)$ & $158(100.0)$ & $175(100.0)$ & $286(100.0)$ & $399(100.0)$ & $114(100.0)$ & \\
\hline $\begin{array}{l}\text { Underweight } \\
(\leq 18.49)\end{array}$ & $78(6.9)$ & $11(7.0)$ & $14(8.0)$ & $25(8.7)$ & $14(3.5)$ & $14(12.3)$ & $0.000 *$ \\
\hline $\begin{array}{l}\text { Normal Weight } \\
(18.50-24.99)\end{array}$ & $510(45.1)$ & $73(46.2)$ & $93(53.1)$ & $125(43.7)$ & 157 (39.3) & $62(54.4)$ & \\
\hline $\begin{array}{l}\text { Overweight (25.00- } \\
29.99)\end{array}$ & $388(34.3)$ & $52(32.9)$ & $61(34.9)$ & $112(39.2)$ & $129(32.3)$ & $34(29.8)$ & \\
\hline Obese $(\geq 30.00)$ & $156(13.8)$ & $22(13.9)$ & $7(4.0)$ & $24(8.4)$ & $99(24.8)$ & $4(3.5)$ & \\
\hline $\begin{array}{l}\text { Tumor Family } \\
\text { History }\end{array}$ & $1911(100.0)$ & $226(100.0)$ & $300(100.0)$ & $548(100.0)$ & $613(100.0)$ & $224(100.0)$ & \\
\hline Yes & $81(4.2)$ & $12(5.3)$ & $22(7.3)$ & $18(3.3)$ & $21(3.4)$ & $8(3.6)$ & $0.037^{*}$ \\
\hline No & $1830(95.8)$ & 214 (94.7) & $278(92.7)$ & $530(96.7)$ & $592(96.6)$ & $216(96.4)$ & \\
\hline Smoking Status & $1844(100.0)$ & $233(100.0)$ & $288(100.0)$ & $507(100.0)$ & $592(100.0)$ & $224(100.0)$ & \\
\hline Smoker & 533 (28.9) & $106(45.5)$ & 114 (39.6) & 139 (27.4) & 114 (19.3) & $60(26.8)$ & $0.000 *$ \\
\hline Non-smoker & $1311(71.1)$ & $127(54.5)$ & $174(60.4)$ & $368(72.6)$ & 478 (80.7) & $164(73.2)$ & \\
\hline $\begin{array}{l}\text { Alcohol Drinking } \\
\text { Status }\end{array}$ & $1833(100.0)$ & $232(100.0)$ & $285(100.0)$ & $504(100.0)$ & $590(100.0)$ & $222(100.0)$ & \\
\hline Drinker & $427(23.3)$ & $73(31.5)$ & $80(28.1)$ & $125(24.8)$ & $99(16.8)$ & $50(22.5)$ & $0.000 *$ \\
\hline Non-drinker & $1406(76.7)$ & $159(68.5)$ & 205 (71.9) & $379(75.2)$ & $491(83.2)$ & $172(77.5)$ & \\
\hline
\end{tabular}

* Significantly different, using Kruskal-Wallis test, Mantel-Haenszel $\chi^{2}$ test or Fisher's exact tests.

also partly due to the inferior radiographic and endoscopic techniques. We found that NENs of the upper digestive tract were more common in rural residents, while NENs of the rectum and pancreas were more common among urban residents. According to the annual cancer reports in China from 2007-2010 [15], the incidence of gastric neoplasms was over one-fold higher in rural than that among urban residents, while colorectal neoplasms had almost 1.5 -fold 
higher incidence in urban residents. As denocarcinoma and NENs from the same sites may share similar risk factors, the different predilection part of digestive tract may also have something to do with the nutrition level as some papers reported before [20]. Also, relating screening programs on upper digestive tumors were more frequently in rural than in urban could be another reason. The high incidence of upper digestive tract NEN incidence in rural area could partially explain the high incidence of gastric NENs in mainland China. On the other hand, The NEN patients of all sites were increasing during the past decade, and the better acknowledgment of doctors and diagnose capacity may be the main reasons. Pancreatic and rectum NENs were more likely to be symptomatic, and the case number increased more significantly. The remarkable case number increase in urban patients revealed the unequal development of medical recourses.

The diagnosis age for Chinese GEP-NEN patients was about 10 years younger than that of Americans (53.0 years vs. 62.0 years) [8] for all primary sites, especially for pancreatic NENs (45.7 years VS. 59.0 years). We also found that sex ratios of different anatomic sites varied greatly: male patients comprised most cardiac and gastric body NEN patients and a smaller majority in rectal NEN patients; female patients dominated in pancreatic NENs. Similar but less extreme sex ratios were reported in the Taiwanese study [13]. In western countries and American $[8,21]$, gastric NENs occurred equally in males and females, while males continued to dominate in rectal and pancreatic NENs.

Large disparities were also found between Asia and America [8] in terms of clinical stage and histology grade; almost $70 \%$ of gastric NENs in our study were at the regional or distant stage, while this proportion was only 30\% in America. Rectal NENs were also diagnosed at later stage in our study; the proportion of NENs in the local stage was $72.4 \%$ vs. $92 \%$ in America. Most pancreatic NENs were benign, local, and graded as G1 when diagnosed in our study and in Japan [12], while in America, $64 \%$ of patients were at the distant metastasis stage [8].

It has been reported that surgery is the only potentially curative therapy for GEP-NENs [22-24], chemotherapy is effective for poorly-differentiated NENs [25-27], and biological therapy proved to be effective in some studies for reducing hormone-related symptoms [28, 29]. In our study, surgery was the most common therapy; chemotherapy was used frequently for cardiac and gastric body NENs, while biological therapy was only used in some patients with pancreatic NENs. Other therapeutic options, such as targeted therapy and radiotherapy, were rarely used in China. The distribution of most prognosis related [30-32] pathological features and biomarker detection rates differed according to anatomic site in our study too.

These findings must be considered in the light of the study's strengths and weaknesses. Firstly, as a multicenter study, the case number was large and the hospitals were geographically represented. Secondly, the variables we collected covered parameters of epidemiology, clinical presentation, diagnosis, and pathology, providing a fairly complete profile of the GEP-NEN patients. Thirdly, we used basic indicators and the newest classification standard to reduce information bias. The main limitations were: first, the hospitals included were convenience-sampled, and they were more likely to be in advanced medical level. Some early-stage lesions removed surgically in local hospitals may be missed. Secondly, we have no comparison group to evaluate risk factors. Finally, data quality depended partially on the integrity of the medical records.

In summary, we found that in Chinese tertiary hospitals, pancreatic and rectal NENs comprised the majority
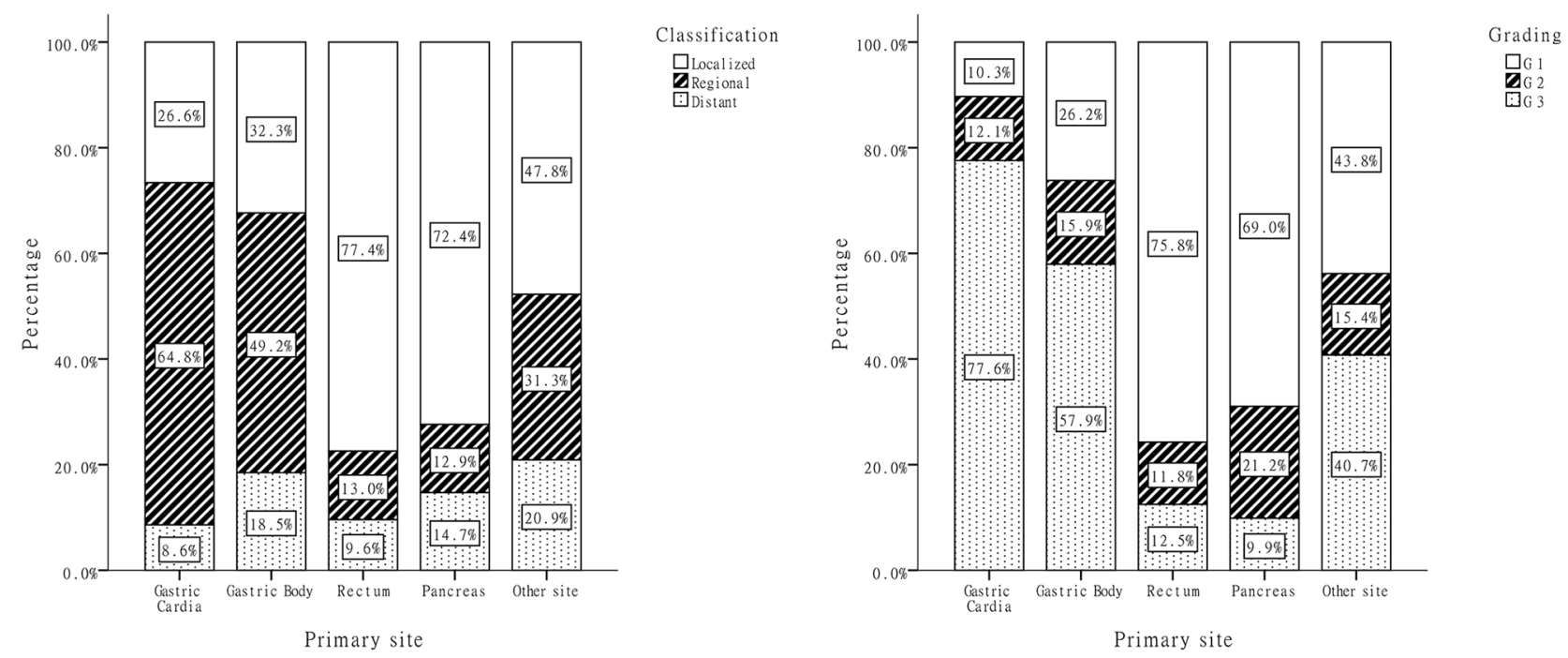

Figure 3: Distribution of classification and grade by primary anatomic sites. 
Table 2: Surgery and other therapy information of NENs from different anatomic sites

\begin{tabular}{|c|c|c|c|c|c|c|c|}
\hline Treatment method & $\begin{array}{c}\text { Total } \\
\text { distribution } \\
(\mathrm{N}=\mathbf{2 0 1 0})\end{array}$ & $\begin{array}{c}\text { Gastric } \\
\text { cardiac NENs } \\
(\mathrm{N}=\mathbf{2 3 4})\end{array}$ & $\begin{array}{c}\text { Gastric } \\
\text { body NENs } \\
(\mathbf{N}=\mathbf{3 0 9})\end{array}$ & $\begin{array}{c}\text { Rectal } \\
\text { NENs } \\
(\mathbf{N}=\mathbf{5 9 5})\end{array}$ & $\begin{array}{c}\text { Pancreatic } \\
\text { NENs } \\
(\mathrm{N}=633)\end{array}$ & $\begin{array}{c}\text { Other } \\
\text { NENs } \\
(\mathrm{N}=239)\end{array}$ & $P$ value \\
\hline & n $(\%)$ & n $(\%)$ & n $(\%)$ & n $(\%)$ & n $(\%)$ & n $(\%)$ & \\
\hline Surgery type & $1820(100.0)$ & $225(100.0)$ & $265(100.0)$ & $533(100.0)$ & $585(100.0)$ & $212(100.0)$ & \\
\hline Radical surgery & $1699(93.4)$ & $221(98.2)$ & $246(92.8)$ & $481(90.2)$ & $562(96.1)$ & $189(89.2)$ & $0.000 *$ \\
\hline Palliative surgery & $121(6.6)$ & $4(1.8)$ & $19(7.2)$ & $52(9.8)$ & $23(3.9)$ & $23(10.8)$ & \\
\hline Surgery method & $1699(100.0)$ & $204(100.0)$ & $265(100.0)$ & $464(100.0)$ & $555(100.0)$ & $211(100.0)$ & \\
\hline Open surgery & $1446(85.1)$ & $199(97.5)$ & $241(90.9)$ & $309(66.6)$ & $507(91.4)$ & $190(90.0)$ & $0.000 *$ \\
\hline Laparoscopic surgery & $107(6.3)$ & $5(2.5)$ & $19(7.2)$ & $23(5.0)$ & $47(8.5)$ & $13(6.2)$ & \\
\hline Endoscopic surgery & $146(8.6)$ & $0(0)$ & $5(1.9)$ & $132(28.4)$ & $1(0.2)$ & $8(3.8)$ & \\
\hline Chemotherapy & $1967(100.0)$ & $224(100.0)$ & $304(100.0)$ & $579(100.0)$ & $627(100.0)$ & $233(100.0)$ & \\
\hline Yes & $393(20.0)$ & $82(36.6)$ & $115(37.8)$ & $72(12.4)$ & $69(11.0)$ & $55(23.6)$ & $0.000 *$ \\
\hline No & $1574(80.0)$ & $142(63.4)$ & $189(62.2)$ & $507(87.6)$ & $558(89.0)$ & $178(76.4)$ & \\
\hline Biotherapy & $1982(100.0)$ & $231(100.0)$ & $307(100.0)$ & $589(100.0)$ & $621(100.0)$ & $234(100.0)$ & \\
\hline Yes & $195(9.8)$ & $0(0)$ & $6(2.0)$ & $3(0.5)$ & $171(27.5)$ & $15(6.4)$ & $0.000^{*}$ \\
\hline No & 1787 (90.2) & $231(100.0)$ & $301(98.0)$ & $586(99.5)$ & $450(72.5)$ & $219(93.6)$ & \\
\hline Target therapy & $1980(100.0)$ & $226(100.0)$ & 305 (100.0) & $585(100.0)$ & $629(100.0)$ & $235(100.0)$ & \\
\hline Yes & $14(0.7)$ & $0(0)$ & $6(2.0)$ & $0(0)$ & $6(1.0)$ & $2(0.9)$ & $0.004 *$ \\
\hline No & $1966(99.3)$ & $226(100.0)$ & $299(98.0)$ & $585(100.0)$ & $623(99.0)$ & $233(99.1)$ & \\
\hline Radiotherapy & $1997(100.0)$ & $231(100.0)$ & $308(100.0)$ & $590(100.0)$ & $632(100.0)$ & $236(100.0)$ & \\
\hline Yes & $43(2.2)$ & $7(3.0)$ & $5(1.6)$ & $20(3.4)$ & $5(0.8)$ & $6(2.5)$ & $0.024^{*}$ \\
\hline No & $1954(97.8)$ & $224(97.0)$ & $303(98.4)$ & $570(96.6)$ & 627 (99.2) & $230(97.5)$ & \\
\hline
\end{tabular}

* Significantly different, using Mantel-Haenszel $\chi^{2}$ test or Fisher's exact tests.

Table 3: Pathological features and immunohistochemistry results of certain biomarkers of NENs

\begin{tabular}{|c|c|c|c|c|c|c|c|}
\hline $\begin{array}{l}\text { Clinical and Pathological } \\
\text { features }\end{array}$ & $\begin{array}{c}\text { Total } \\
\text { distribution } \\
(\mathrm{N}=\mathbf{2 0 1 0})\end{array}$ & $\begin{array}{c}\text { Gastric } \\
\text { cardiac } N E N s \\
(\mathrm{~N}=234)\end{array}$ & $\begin{array}{c}\text { Gastric } \\
\text { body NENs } \\
(\mathrm{N}=309)\end{array}$ & $\begin{array}{c}\text { Rectal } \\
\text { NENs } \\
(\mathbf{N}=\mathbf{5 9 5})\end{array}$ & $\begin{array}{c}\text { Pancreatic } \\
\text { NENs } \\
(\mathrm{N}=633)\end{array}$ & $\begin{array}{c}\text { Other } \\
\text { NENs } \\
(\mathbf{N}=\mathbf{2 3 9})\end{array}$ & $P$ value \\
\hline & $\begin{array}{l}\text { n }(\text { Positive } \\
\text { rate } \%)\end{array}$ & $\begin{array}{l}\text { n }(\text { Positive } \\
\text { rate } \%)\end{array}$ & $\begin{array}{l}\text { n }(\text { Positive } \\
\text { rate } \%)\end{array}$ & $\begin{array}{c}\text { n }(\text { Positive } \\
\text { rate } \%)\end{array}$ & $\begin{array}{l}\text { n }(\text { Positive } \\
\text { rate } \%)\end{array}$ & $\begin{array}{l}\text { n }(\text { Positive } \\
\text { rate } \%)\end{array}$ & \\
\hline Vascular space involvement & $1390(13.8)$ & $209(22.0)$ & $252(19.0)$ & $497(5.2)$ & $258(17.4)$ & $174(15.5)$ & $0.000^{*}$ \\
\hline Perineural invasion & $1378(5.2)$ & $207(5.8)$ & $250(6.8)$ & $493(1.8)$ & $256(9.0)$ & $172(6.4)$ & $0.000 *$ \\
\hline Necrosis & $1391(9.1)$ & $208(13.9)$ & $249(13.3)$ & $499(3.8)$ & $266(11.3)$ & $169(9.5)$ & $0.000 *$ \\
\hline Cystic degeneration & $1368(2.6)$ & $204(1.5)$ & $241(0.4)$ & $490(0.8)$ & $266(9.8)$ & $167(1.2)$ & $0.000 *$ \\
\hline Synaptophysin & $1296(90.0)$ & $168(91.1)$ & $215(89.3)$ & $410(88.8)$ & $327(93.3)$ & $176(86.9)$ & 0.149 \\
\hline Choromogranin A & $1243(67.6)$ & $148(62.8)$ & $192(75.0)$ & $371(52.3)$ & $376(81.6)$ & $156(65.4)$ & $0.000 *$ \\
\hline CD56 & $532(79.7)$ & $94(80.9)$ & $111(75.7)$ & $143(77.6)$ & $117(89.7)$ & $67(71.6)$ & $0.021 *$ \\
\hline Neuron-specific enolase & $612(78.8)$ & $78(65.4)$ & $99(67.7)$ & $218(85.3)$ & $135(83.7)$ & $82(79.3)$ & $0.000 *$ \\
\hline S-100 protein & $205(41.0)$ & $26(26.9)$ & $33(45.5)$ & $64(48.8)$ & $49(34.7)$ & $33(42.4)$ & 0.32 \\
\hline CK(AE1/AE3) & $940(79.1)$ & $122(82.0)$ & $165(86.1)$ & $300(82.7)$ & $227(70.5)$ & $126(74.6)$ & $0.001 *$ \\
\hline
\end{tabular}

* Significantly different, using Mantel-Haenszel $\chi^{2}$ test or Fisher's exact tests. 
of all GEP-NENs, and the sex, age, stage and grade were various depending on the primary neoplasm sites. Multiple examination and treatment were limited in the current clinical course. Our results provide primary data on GEP-NEN patients in China, and suggest the different epidemiology and clinical features of GEP-NENs in China and other countries. Additional observation studies with more superior sampling methods are needed to confirm these findings.

\section{MATERIALS AND METHODS}

\section{Study design}

This study was a hospital-based, multi-center, retrospective study over 10 years (2001-2010). All GEPNEN patients with confirmed pathology from the selected hospitals were included for analysis.

\section{Selection of hospitals and patients}

China was divided into seven geographical regions based on traditional administration: North, North-East, Central, South, East, North-West and South-West. At least one cancer hospital and one general hospital were selected from each region. Convenience sampling was used to choose hospitals from each region. The inclusion criteria for hospitals included: (1) at tertiary level which cover patients from different parts of the region; (2) easy retrieval of information on GEP-NEN patients and (3) a local team with the ability to complete the case report form. The inclusion criteria for patients included (1) pathological diagnosed as GEP-NEN patients in the years 2001-2010; and (2) possessing complete medical records. All eligible records from the selected hospitals were reviewed based on the designed case report form (CRF). This study was approved by the Institutional Review Board of the Cancer Hospital, Chinese Academy of Medical Sciences.

\section{Data collection and quality control}

The case report form was designed by professionals of epidemiology, pathology, internal medicine, surgery, imaging, and radiotherapy, and the pilot study was conducted in CHCAMS. The questions in case report form included eight aspects: (1) general administrative information; (2) demographic characteristics and possible risk factors at the time of diagnosis, including age, gender, height and weight, occupation, education and marital status, household registration, family history of tumor (whether malignant or benign, occurred on parents or siblings), smoking and drinking status (have the habits of smoking or drinking now, whether how long the history is); (3) linical features, including primary tumor sites and clinical syndromes; (4) results of imaging tests, including transabdominal ultrasound, computed tomography, endoscopy and ultrasound endoscopy; (5) use of currently available treatment approaches, including surgery, chemotherapy, biological therapy and target therapy; (6) pathological characteristics, including tumor size, infiltration limits, mitosis rate, Ki-67 labeling index, vascular space involvement; (7) immunohistochemical results of biomarker tests, including synaptophysin, choromogranin A, and neuronspecific enolase.

All information was abstracted from the medical records by a trained local doctor. Two copies of data set entered by two clerks via EpiData were sent to the study center in CHCAMS. Consistency validation and logistical checks were carried out and the final database was used for analysis. De-identified data were stored in a security database (FoxPro) via a recognizable series of index numbers. There data were accessible only to researchers and will be reported in aggregate.

\section{Data processing}

The staging system applied to NENs during the last decade was not unified [33, 34], so we used the basic information (including tumor site, size, lymph node involvement, invasion range, and metastatic status) that determines tumor staging to reclassify the 2,010 cases as localized, regional, or distant. Localized NENs are confined entirely to the original organ; regional NENs meet at least one of the following conditions: (1) the tumors invaded surrounding organs or tissues or (2) the tumors involved regional lymph nodes; and distant NENs spread to other body parts remote from the primary tumor site. Tumor grade was determines by $\mathrm{Ki}-67$ index or mitotic count, if both results were available, the higher one was taken.

\section{Data analysis}

Patients' age was tested for normality using the one-sample Kolmogorov-Smirnov test, and the KruskalWallis test were used to compare the median of each group. Discrete variables were examined using MantelHaenszel chi-square tests and Fisher's exact tests to obtain $P$ values. SPSS statistical software version 17.0 (SPSS Inc. Chicago, IL, USA) was used to analyze the data. Statistical significance was assessed by two-tailed tests with $\alpha$ level of 0.05 .

\section{Abbreviations}

GEP-NEN, Gastroenteropancreatic Neuroendocrine Neoplasm;

WHO, World Health Organization;

ENETS, the European Neuroendocrine Tumor Society;

AJCC/UICC, the American Joint International Cancer/ Union of International Cancer; 
SEER, the Surveillance, Epidemiology, and End Results;

CRF, Case Report Form;

\section{Author contributions}

Jin-Hu Fan: Conception and design, quality control and manuscript writing; Yu-Qing Zhang: Data analysis and interpretation and manuscript writing; Su-Sheng Shi, Yuan-Jia Chen, Xing-Hua Yuan, Li-Ming Jiang, ShaoMing Wang: Led the study design and contribution to the interpretation of the findings; Li Ma, Yu-Tong He, ChangYan Feng, Xi-Bin Sun, Qing Liu: Local data collection; Katrina Deloso: Help with the language; Yihebali Chi, You-Lin Qiao: Conception and design, Financial and administrative support. All authors read and approved the final manuscript.

\section{ACKNOWLEDGMENTS}

We acknowledge the work of local investigators from cooperative hospitals, and the expertise from JianQiang Cai, Gui-Qi Wang, Dong-Bing Zhao and Hong Zhao in Chinese Neuroendocrine Tumor Society (CNETS) was also gratefully acknowledged.

\section{CONFLICTS OF INTEREST}

All the authors state that they have no conflicts of interest, financial or otherwise.

\section{FUNDING}

Pfizer provided funding but had no role in the design and conduct of the study.

\section{REFERENCES}

1. Oberndorfer S. Karzinoide Tumoren des Dunndarms. Frankf Z Pathol. 1907; 1: 426-32.

2. Williams ED, Sandler M. The classification of carcinoid tum ours. Lancet. 1963; 1: 238-9.

3. Heitz P, Komminoth P, Perren A, Klimstra D, Dayal Y. Pancreatic endocrine tumors: introduction. Pathology and genetics: tumors of endocrine organs. 2004: 177-82.

4. Rindi G, Kloppel G, Alhman H, Caplin M, Couvelard A, de Herder WW, Erikssson B, Falchetti A, Falconi M, Komminoth P, Korner M, Lopes JM, McNicol AM, et al. TNM staging of foregut (neuro) endocrine tumors: a consensus proposal including a grading system. Virchows Arch. 2006; 449: 395-401. doi: 10.1007/ s00428-006-0250-1.

5. Rindi G, Kloppel G, Couvelard A, Komminoth P, Korner M, Lopes JM, McNicol AM, Nilsson O, Perren A, Scarpa A, Scoazec JY, Wiedenmann B. TNM staging of midgut and hindgut (neuro) endocrine tumors: a consensus proposal including a grading system. Virchows Arch. 2007; 451: 757-62. doi: 10.1007/s00428-007-0452-1.

6. Strosberg JR, Cheema A, Weber JM, Ghayouri M, Han G, Hodul PJ, Kvols LK. Relapse-free survival in patients with nonmetastatic, surgically resected pancreatic neuroendocrine tumors: an analysis of the AJCC and ENETS staging classifications. Ann Surg. 2012; 256: 3215. doi: 10.1097/SLA.0b013e31824e6108.

7. Turaga KK, Kvols LK. Recent progress in the understanding, diagnosis, and treatment of gastroenteropancreatic neuroendocrine tumors. CA Cancer J Clin. 2011; 61: 113-32. doi: 10.3322/caac.20097.

8. Yao JC, Hassan M, Phan A, Dagohoy C, Leary C, Mares JE, Abdalla EK, Fleming JB, Vauthey JN, Rashid A, Evans DB. One hundred years after "carcinoid": epidemiology of and prognostic factors for neuroendocrine tumors in 35,825 cases in the United States. J Clin Oncol. 2008; 26: 3063-72. doi: 10.1200/JCO.2007.15.4377.

9. Lawrence B, Gustafsson BI, Chan A, Svejda B, Kidd M, Modlin IM. The epidemiology of gastroenteropancreatic neuroendocrine tumors. Endocrinol Metab Clin North Am. 2011; 40: 1-18, vii. doi: 10.1016/j.ecl.2010.12.005.

10. Ellis L, Shale M, Coleman M. Carcinoid tumors of the gastrointestinal tract: trends in incidence in England since 1971. Am J Gastroenterol. 2010; 105: 2563-9. doi: 10.1038/ ajg.2010.341.

11. Cho MY, Kim JM, Sohn JH, Kim MJ, Kim KM, Kim WH, Kim H, Kook MC, Park do Y, Lee JH, Chang H, Jung ES, Kim HK, et al. Current Trends of the Incidence and Pathological Diagnosis of Gastroenteropancreatic Neuroendocrine Tumors (GEP-NETs) in Korea 2000-2009: Multicenter Study. Cancer Res Treat. 2012; 44: 157-65. doi: 10.4143/crt.2012.44.3.157.

12. Ito $\mathrm{T}$, Igarashi H, Nakamura $\mathrm{K}$, Sasano H, Okusaka T, Takano K, Komoto I, Tanaka M, Imamura M, Jensen RT, Takayanagi R, Shimatsu A. Epidemiological trends of pancreatic and gastrointestinal neuroendocrine tumors in Japan: a nationwide survey analysis. J Gastroenterol. 2015; 50: 58-64. doi: 10.1007/s00535-014-0934-2.

13. Tsai HJ, Wu CC, Tsai CR, Lin SF, Chen LT, Chang JS. The epidemiology of neuroendocrine tumors in Taiwan: a nation-wide cancer registry-based study. PLoS One. 2013; 8: e62487. doi: 10.1371/journal.pone.0062487.

14. Chen WQ ZR, Zeng HM, Zhang SW, Zhao P, He J. Trend analysis and projection of cancer incidence in China between 1989 and 2008. Chin J Oncol. 2012; 34: 517-24.

15. J H, WQ C. Chinese Cancer Registry Annual Report 2013. Military Medical Science Press. 2013.

16. Zhang X, Ma L, Bao H, Zhang J, Wang Z, Gong P. Clinical, pathological and prognostic characteristics of gastroenteropancreatic neuroendocrine neoplasms in China: a retrospective study. BMC Endocr Disord. 2014; 14: 54. doi: 10.1186/1472-6823-14-54. 
17. Wang YH, Lin Y, Xue L, Wang JH, Chen MH, Chen J. Relationship between clinical characteristics and survival of gastroenteropancreatic neuroendocrine neoplasms: A single-institution analysis (1995-2012) in South China. BMC Endocr Disord. 2012; 12: 30. doi: 10.1186/1472-6823-12-30.

18. Hauso O, Gustafsson BI, Kidd M, Waldum HL, Drozdov I, Chan AK, Modlin IM. Neuroendocrine tumor epidemiology: contrasting Norway and North America. Cancer. 2008; 113: 2655-64. doi: 10.1002/cncr.23883.

19. Levi F, Te VC, Randimbison L, Rindi G, La Vecchia C. Epidemiology of carcinoid neoplasms in Vaud, Switzerland, 1974-97. Br J Cancer. 2000; 83: 952-5. doi: 10.1054/ bjoc. 2000.1394.

20. Cheng Yi-Kun YS-M, Xu Yi-Ran, Niu Run-Gui. Life-Style Habits in a High-Risk Area for Upper Gastrointestinal Cancers: a Population-Based Study from Shanxi, China. Asian Pac J Cancer Prev,. 2016; 17: 4301-6.

21. Fraenkel M, Kim M, Faggiano A, de Herder WW, Valk GD, Knowledge N. Incidence of gastroenteropancreatic neuroendocrine tumours: a systematic review of the literature. Endocr Relat Cancer. 2014; 21: R153-63. doi: 10.1530/ERC-13-0125.

22. org N. Neuroendocrine Tumors. NCCN Clinical Practice Guidelines in Oncology. 2014; Version 2.2014.

23. Modlin IM, Latich I, Kidd M, Zikusoka M, Eick G. Therapeutic options for gastrointestinal carcinoids. Clin Gastroenterol Hepatol. 2006; 4: 526-47. doi: 10.1016/j. cgh.2005.12.008.

24. Kulke MH, Siu LL, Tepper JE, Fisher G, Jaffe D, Haller DG, Ellis LM, Benedetti JK, Bergsland EK, Hobday TJ, Van Cutsem E, Pingpank J, Oberg K, et al. Future directions in the treatment of neuroendocrine tumors: consensus report of the National Cancer Institute Neuroendocrine Tumor clinical trials planning meeting. J Clin Oncol. 2011; 29: 934-43. doi: 10.1200/JCO.2010.33.2056.

25. Modlin IM, Oberg K, Chung DC, Jensen RT, de Herder WW, Thakker RV, Caplin M, Delle Fave G, Kaltsas GA, Krenning EP, Moss SF, Nilsson O, Rindi G, et al. Gastroenteropancreatic neuroendocrine tumours. The Lancet Oncology. 2008; 9: 61-72. doi: 10.1016/ s1470-2045(07)70410-2.

26. Cives M, Strosberg J. An update on gastroenteropancreatic neuroendocrine tumors. Oncology (Williston Park). 2014; 28: 749-56, 58.

27. Heetfeld M, Chougnet CN, Olsen IH, Rinke A, Borbath I, Crespo G, Barriuso J, Pavel M, O'Toole D, Walter T. Characteristics and treatment of patients with G3 gastroenteropancreatic neuroendocrine neoplasms. Endocr Relat Cancer. 2015. doi: 10.1530/erc-15-0119.

28. Oberg K. Consensus report on the use of somatostatin analogs for the management of neuroendocrine tumors of the gastroenteropancreatic system. Annals of Oncology. 2004; 15: 966-73. doi: 10.1093/annonc/mdh216.

29. Oberg K. Future aspects of somatostatin-receptor-mediated therapy. Neuroendocrinology. 2004; 80: 57-61. doi: 10.1159/000080743.

30. Rindi G, D'Adda T, Froio E, Fellegara G, Bordi C. Prognostic factors in gastrointestinal endocrine tumors. Endocr Pathol. 2007; 18: 145-9. doi: 10.1007/ s12022-007-0020-x.

31. Rindi G, Wiedenmann B. Neuroendocrine neoplasms of the gut and pancreas: new insights. Nat Rev Endocrinol. 2012; 8: 54-64. doi: 10.1038/nrendo.2011.120.

32. Klimstra DS, Modlin IR, Adsay NV, Chetty R, Deshpande V, Gonen M, Jensen RT, Kidd M, Kulke MH, Lloyd RV, Moran C, Moss SF, Oberg K, et al. Pathology reporting of neuroendocrine tumors: application of the Delphic consensus process to the development of a minimum pathology data set. Am J Surg Pathol. 2010; 34: 300-13. doi: 10.1097/PAS.0b013e3181ce1447.

33. Capelli P, Fassan M, Scarpa A. Pathology - grading and staging of GEP-NETs. Best Pract Res Clin Gastroenterol. 2012; 26: 705-17. doi: 10.1016/j.bpg.2013.01.003.

34. Kloppel G. Classification and pathology of gastroenteropancreatic neuroendocrine neoplasms. Endocr Relat Cancer. 2011; 18: S1-16. doi: 10.1530/ERC-11-0013. 